\section{Cureus}

Received 01/30/2019

Review began 02/06/2019

Review ended 03/26/2019

Published 04/03/2019

\section{(C) Copyright 2019}

Ahmed et al. This is an open access article distributed under the terms of the Creative Commons Attribution License CC-BY 3.0., which permits unrestricted use, distribution, and reproduction in any medium, provided the original author and source are credited.

\title{
Evaluating the Association Between the Extent of Resection and Survival in Gliosarcoma
}

Fahad I. Ahmed ${ }^{1}$, Kalil G. Abdullah ${ }^{1}$, Joseph Durgin ${ }^{1}$, Ryan D. Salinas ${ }^{1}$, Donald M. O'Rourke 1 , Steven Brem ${ }^{1}$

1. Neurosurgery, Hospital of the University of Pennsylvania, Philadelphia, USA

$\square$ Corresponding author: Fahad I. Ahmed, fahadah@sas.upenn.edu

Disclosures can be found in Additional Information at the end of the article

\section{Abstract}

Introduction: Gliosarcoma (GS) is a rare, malignant mixed tumor of the central nervous system with a median survival of approximately 13 months across multiple studies. Although the value of the extent of resection (EOR) has been confirmed as a prognostic survival factor in glioblastoma, no such association has been defined for GS. The goal of this study was to establish an association between EOR and survival and to determine if a threshold of resection exists for which a survival benefit is conferred in GS.

Methods: The authors identified 11 patients with histologically confirmed GS between January 2005 and January 2015, treated at the Hospital of the University of Pennsylvania. Clinical, radiographic, and outcome data were retrospectively reviewed. Volumetric analysis was completed using semi-automated segmentation to measure the change in contrast-enhancing material based on preoperative T1-contrast (T1c) and postoperative T1 \& T1c magnetic resonance imaging (MRI) scans. A log-rank test was completed to confirm an association between EOR and survival, and a series of Kaplan-Meier curves were constructed to determine an EOR threshold. Univariate Cox proportional hazards model (CPHM) followed by multivariate CPHM was also completed to evaluate associations between the prognostic clinical and immunohistochemistry variables under consideration.

Results: Extent of resection categories were defined as gross total resection (GTR >95\%), subtotal resection (STR 90\%-95\%), and partial resection (PR <90\%). The median overall survival for the groups were as follows: GTR-17.3 months ( $n=4)$, STR-12.6 months ( $n=5), P R-4.3$ months $(n=2)$. A statistically significant association ( $p=05$ level) was found between survival and the $P R$ group with the GTR group as reference. Multivariate CPHM confirmed a statistically significant association between increased survival and age, preoperative Karnofsky Performance Status (KPS) scores, postoperative KPS scores, and KI-67 index. Serial Kaplan-Meier curves suggest a survival benefit with an EOR threshold of $94 \%$.

Conclusion: This study agrees with previous correlations in glioblastoma EOR and prolonged survival. For patients undergoing surgical resection for GS, maximal surgical removal, when safely possible, should be attempted as it appears to translate to longer survival times.

Categories: Neurosurgery

Keywords: gliosarcoma, high-grade glioma, gliosarcoma survival, extent of resection 


\section{Introduction}

Gliosarcoma (GS) is a rare form of glioblastoma with unique pathological indicators that has an increased propensity to metastasize outside of the cerebrum. It is a primary mixed tumor, consisting of both sarcomatous and glial elements. Median survival time is approximately 13 months [1]. Histopathology confirms approximately $2 \%$ of diagnosed high-grade gliomas to be GSs [2]. Consequently, knowledge of the disease is based on small retrospective studies and is generally limited.

In this study, we attempt to establish an association with the extent of resection (EOR) and survival in GS patients. In addition, we analyze immunohistochemistry characteristics to determine if an association with any biomolecular markers exists with increased survival.

\section{Materials And Methods}

\section{Study design}

Between January 2005 and January 2015, 11 patients who underwent index resection for GS at the Hospital of the University of Pennsylvania met inclusion data for this retrospective cohort study. None of the patients in our study underwent previous resection operations, nor did they have a previously identified low-grade tumor. Pathology review was completed based on the World Health Organization (WHO) guidelines to confirm all patients had high-grade GS. Clinical, radiographic, and outcome data were retrospectively collected from patient records. The institutional review board of the University of Pennsylvania (IRB \#825635) approved this study.

\section{Imaging analysis}

Tumor volume was measured using a semi-automated segmentation procedure in the ITK-Snap software package (CBICA, Philadelphia, Pennsylvania, USA). The classification extension of the program was used to measure the contrast enhancing material based on preoperative T1contrast (T1c) and postoperative T1 \& T1c magnetic resonance imaging (MRI) scans. The extent of resection was calculated using the following formula: (preoperative tumor volume postoperative tumor volume)/ preoperative tumor volume). The software extension required us to define tumor boundaries by marking regions as within or outside the tumor, allowing the algorithm to mark the tumor in an iterative process. Once the algorithm completed tumor marking, we reviewed the results and modified the segmentation as necessary to ensure proper results. This segmentation was completed without knowledge of patient outcomes.

\section{Statistical analysis}

We constructed Kaplan-Meier curves to show differing survival among EOR categories. A paired log-rank (Mantel-Cox) test was completed to determine statistical significance among survival times between EOR groups, using the gross total resection (GTR) group as reference. To determine an EOR threshold, we created a series of Kaplan-Meier curves at $2 \%$ resection intervals, and the first point at which two survival curves intersected was selected as the point of an EOR threshold. Two approaches were used to determine the prognostic value of the variables considered. Firstly, the Cox proportional hazards model (CPHM) was used to determine if the following factors had a statistically significant relationship with survival: age, gender, preoperative tumor volume, postoperative tumor volume, evidence of metastasis, chemotherapy, preoperative Karnofsky Performance Status (KPS), postoperative KPS, epidermal growth factor receptor (EGFR) (+/-), p53 (+/wt), glial fibrillary acidic protein (GFAP) $(+/-)$, isocitrate dehydrogenase (IDH1) (+/-), and Ki-67 index. A forward stepwise selection technique was used to analyze any characteristics associated with survival ( $p=.05$ threshold) in univariate CPHM; these variables were then analyzed using multivariate CPHM. Statistical 


\section{Cureus}

analysis was performed using JMP 13.1 (SAS Institute, Cary, North Carolina, USA) and Prism 7 (Graphpad Software, La Jolla, California, USA).

\section{Results}

For the 11 patients diagnosed with GS in this study, overall median survival was 12.6 months (Figure 1). Overall median progression-free survival (PFS) for the group was seven months, but PFS was not found to be a statistically significant predictor of survival. Volumetric analysis

showed a median tumor pre-op volume of $28.6 \mathrm{~cm}^{3}$, and a median tumor post-op volume of 2.1 $\mathrm{cm}^{3}$, both equating to a median extent of resection value of $93 \%$ (Table 1 ).

Immunohistochemical data of patient tumors is displayed in Table 2. Patient demographic and clinical details are summarized in Table 3.

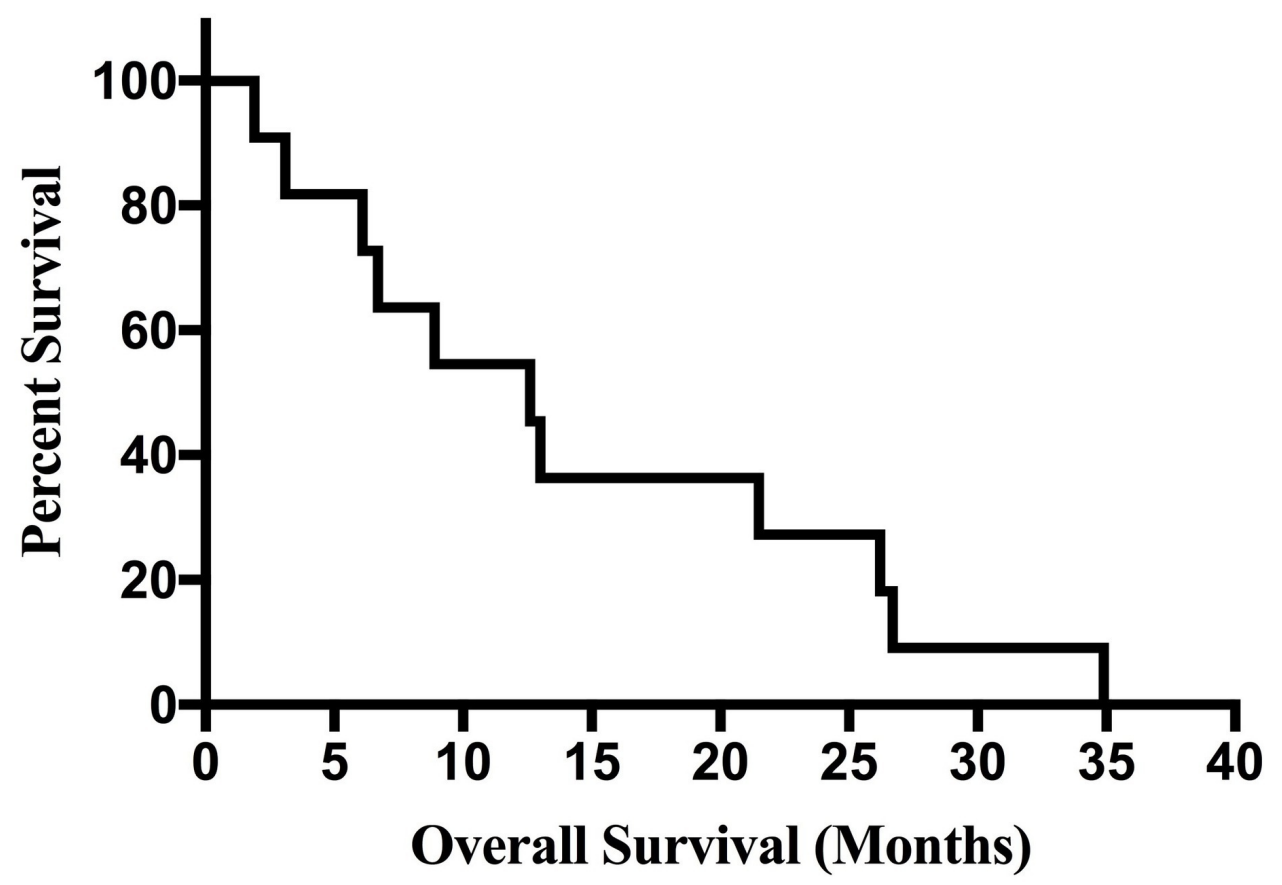

FIGURE 1: Overall Kaplan-Meier Survival Curve

\section{Characteristic}

Age at Diagnosis

Gender

Preoperative Tumor Size $\left(\mathrm{cm}^{3}\right)$

\section{$\mathrm{N}=11$}

$63(54-78)$

Male

$7(64 \%)$

Female

$4(36 \%)$

$1-15$

$1(9 \%)$

$16-30$

$5(46 \%)$

$31-45$

$2(18 \%)$

$>45$

$3(27 \%)$ $p<.001$

\section{P-Value}

NS

NS 


\section{Cureus}

Postoperative Tumor Size $\left(\mathrm{cm}^{3}\right)$

Extent of Resection

Evidence of Metastasis- Intracranial Focality

Evidence of Metastasis- Leptomeningeal Enhancement

Evidence of Metastasis- Extracranial Advancement

Chemoradiotherapy

Preoperative KPS

Postoperative KPS

\begin{tabular}{|c|c|c|}
\hline $0-2.49$ & $7(64 \%)$ & \multirow{3}{*}{ NS } \\
\hline $2.5-5$ & $2(18 \%)$ & \\
\hline $6-10$ & $2(18 \%)$ & \\
\hline > 95\% & $4(36 \%)$ & REF \\
\hline 90- 95\% & $5(46 \%)$ & NS \\
\hline$<90 \%$ & $2(18 \%)$ & $p=.02$ \\
\hline Unifocal & $9(82 \%)$ & \multirow{2}{*}{$p=.03$} \\
\hline Multifocal & $2(18 \%)$ & \\
\hline Present & $2(18 \%)$ & \multirow{2}{*}{ NS } \\
\hline Absent & $9(82 \%)$ & \\
\hline Present & $1(9 \%)$ & \multirow{2}{*}{ NS } \\
\hline Absent & $10(91 \%)$ & \\
\hline No & 1 (9\%) & \multirow{2}{*}{$p=.03$} \\
\hline Yes & $10(91 \%)$ & \\
\hline 90 & $3(27 \%)$ & \multirow{3}{*}{$p=.03$} \\
\hline 80 & $4(36 \%)$ & \\
\hline 70 & $2(18 \%)$ & \\
\hline 100 & $1(9 \%)$ & \multirow{4}{*}{$p=.03$} \\
\hline 90 & $3(27 \%)$ & \\
\hline 80 & $3(27 \%)$ & \\
\hline 70 & $2(18 \%)$ & \\
\hline
\end{tabular}

\section{TABLE 1: Demographics of Patients in Study}

Values provided as median (with range) or absolute number (with percentage). Statistical significance at $p=.05$ level. Karnofsky Performance Status (KPS) scores not available for all patients. 


\section{Cureus}

$\begin{array}{llll}\text { Tumor Characteristic } & & \mathbf{N}= & \text { P-Value } \\ & +1 & 2(18 \%) & \text { NS } \\ \text { EGFR Staining Intensity } & +2 & 1(9 \%) & \\ & +3 & 3(27 \%) & - \\ \text { P53 } & + & 3(27 \%) & \text { NS } \\ & \text { wt } & 9(82 \%) & \\ \text { GFAP } & + & 0(0 \%) & - \\ \text { Mutant IDH1 } & - & 9(82 \%) & 1(9 \%) \\ & + & 0(0 \%) & \text { p } \\ & - & 5(46 \%) & 001\end{array}$

\section{TABLE 2: Immunohistochemical Characteristics}

Values provided as absolute number with percentage. Immunohistochemical data not available for all patients.

EGFR = Epidermal Growth Factor Receptor; P53 = P53 Staining; GFAP = Glial Fibrillary Acidic Protein; IDH1 = Isocitrate Dehydrogenase; KI Index = Antigen Ki-67 Index. 


\section{Cureus}

\begin{tabular}{|c|c|c|c|c|c|c|c|c|}
\hline $\begin{array}{l}\text { Patient } \\
\text { Number }\end{array}$ & $\begin{array}{l}\text { OS } \\
\text { (Months) }\end{array}$ & $\begin{array}{l}\text { Age } \\
\text { (Years) }\end{array}$ & Gender & $\begin{array}{l}\text { Pre/Postop Tumor } \\
\text { Volume }\left(\mathrm{cm}^{3}\right)\end{array}$ & EOR & $\begin{array}{l}\text { Chemo- } \\
\text { RT }\end{array}$ & $\begin{array}{l}\text { Evidence of } \\
\text { Metastasis }\end{array}$ & $\begin{array}{l}\text { Pre/Postop } \\
\text { KPS }\end{array}$ \\
\hline 1 & 8.9 & 63 & $\mathrm{M}$ & $22.2 / .50$ & .98 & + & $(1,-,-)$ & 90/90 \\
\hline 2 & 1.9 & 78 & $\mathrm{~F}$ & 28.6/6.1 & .79 & - & $(2,-,-)$ & 70/- \\
\hline 3 & 13.0 & 63 & M & $60.1 / 2.1$ & .97 & + & $(1,-,-)$ & $80 / 80$ \\
\hline 4 & 3.1 & 78 & $\mathrm{~F}$ & $35.5 / 2.5$ & .93 & + & $(1,-,-)$ & $70 / 70$ \\
\hline 5 & 6.1 & 73 & M & $82.5 / 4.7$ & .94 & + & $(2,-,-)$ & $-1-$ \\
\hline 6 & 21.5 & 59 & $\mathrm{M}$ & 21.8/1.0 & .95 & + & $(1,+,+)$ & $90 / 100$ \\
\hline 7 & 12.6 & 65 & M & 21.1/1.6 & .92 & + & $(1,-,-)$ & $-/ 80$ \\
\hline 8 & 26.2 & 66 & M & 26.0/2.1 & .92 & + & $(1,-,-)$ & $80 / 80$ \\
\hline 9 & 34.9 & 54 & $M$ & $36.6 / 0$ & 1.0 & + & $(1,+,-)$ & $80 / 90$ \\
\hline 10 & 26.7 & 55 & $\mathrm{~F}$ & 65.5/6.6 & .90 & + & $(1,-,-)$ & 90/90 \\
\hline 11 & 6.7 & 56 & $\mathrm{~F}$ & 4.3/1.8 & .58 & + & $(1,-,-)$ & $80 / 70$ \\
\hline
\end{tabular}

\section{TABLE 3: Patient Characteristics}

Evidence of metastasis presented as (Focality, Leptomeningeal Enhancement, Extracerebral Spread); $1=$ Unifocal, $2=$ Multifocal

Extent of resection categories were defined as gross total resection (GTR >95\%), subtotal resection (STR 90\%-95\%), and partial resection (PR <90\%), and the median overall survival for the groups were as follows: GTR-17.3 months, STR-12.6 months, PR-4.3 months (Figure 2). There were four patients in the GTR group, five patients in the STR group, and two patients in the PR group. The paired log-rank test confirmed a statistically significant association, at the $\mathrm{p}=.05$ level, between survival and the $\mathrm{PR}(\mathrm{p}=.01)$ resection group with the GTR group as reference. However, no association was found between survival and the STR group with the GTR group as reference. Univariate CPHM confirmed a statistically significant association between increased survival and age, chemo-radiotherapy, pre-operative KPS, post-operative KPS, focality, and KI Index. Multivariate analysis demonstrated a continued statistical significance for age, preoperative KPS, postoperative KPS, and KI index (Table 4). Serial Kaplan-Meier curves, constructed at 2\% EOR intervals, suggest a survival benefit at an EOR threshold of 94\%. 


\section{Cureus}

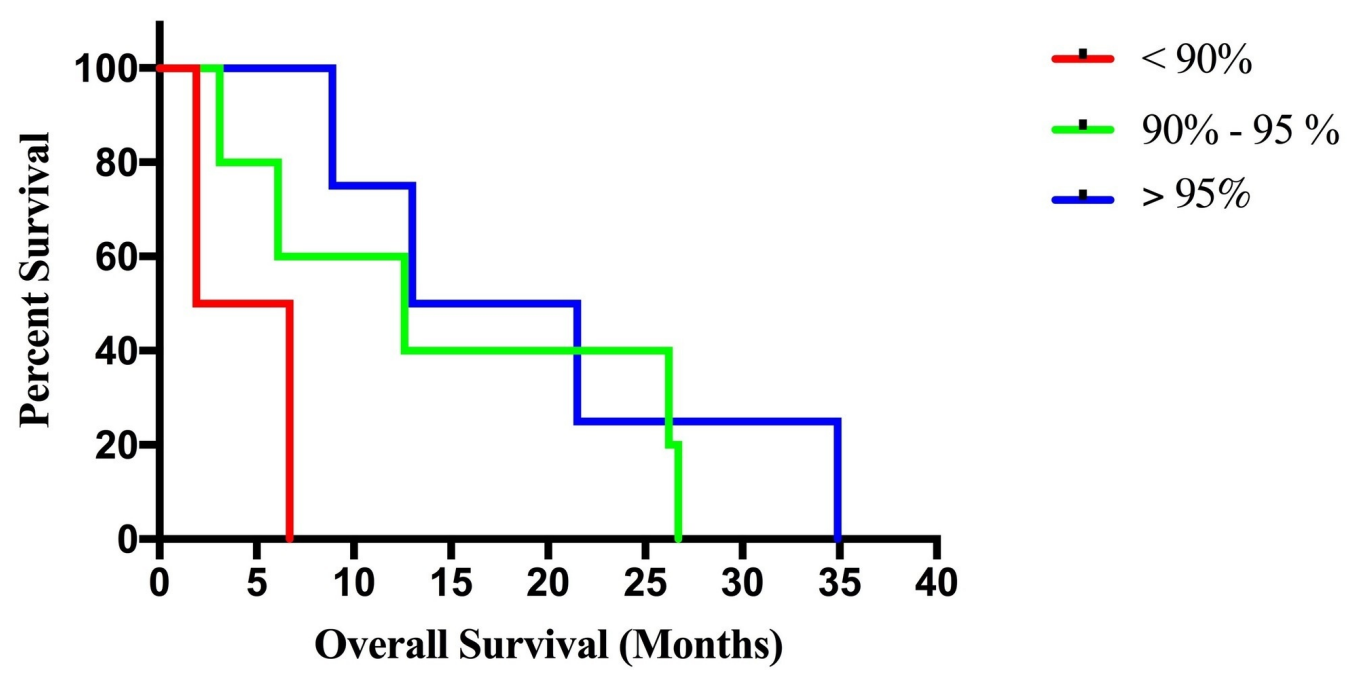

FIGURE 2: Kaplan-Meier Survival Curves Stratified by Extent of Resection (EOR)

Variable

Age

Tumor Focality

Chemoradiotherapy

Preoperative KPS

Postoperative KPS

KI Index
Unit HR (95\% Cl)

$1.21(.99-1.58)$

$-$

.79 (.48- 1.05)

$.84(.59-1.08)$

$1.02(.98-1.08)$

\section{P-Value}

$p=.05$

NS

NS

$p=.04$

$\mathrm{p}<.01$

$\mathrm{p}<.01$

\section{TABLE 4: Results of Multivariate Cox Proportional Hazards Model (CPHM)}

Forward stepwise selected variables from univariate CPHM at the $p=.05$ level. Multivariate CPHM results displayed, with significance at $p=.05$ level. Table indicates unit hazard ratios; unit defined as 1 year in age, 10 on Karnofsky Performance Status (KPS) scale, 1\% on $\mathrm{KI}$ index.

\section{Discussion}

The 2016 updated WHO central nervous system (CNS) guidelines classify tumors by molecular and genetic markers, and group high-grade gliomas by IDH status. GS is classified as an IDHwildtype variant along with giant cell glioblastoma and epithelioid glioblastoma [3]. Histologically, necrosis and endothelial proliferation must be present for the diagnosis of high-grade glioma, and specifically, for diagnosis of GS, tumors must show both glial and mesenchymal differentiation.

The current standard of care for high-grade gliomas primarily is surgical resection followed by 


\section{Cureus}

adjuvant chemoradiotherapy with temozolomide. Median survival time is approximately 6-17.5 months across multiple studies (Table 5). Multiple studies have documented a positive association between extent of resection and survival in glioblastoma patients, and one study suggests a threshold of resection for maximum benefit exists at 80\% [4]; however, to our knowledge, no study exists that defines an EOR threshold for GS. One study [2] utilizing the Surveillance, Epidemiology, and End Results (SEER) database suggests age, the extent of resection, and use of adjuvant radiotherapy to be associated with increased survival in GS. Determining an appropriate surgical treatment paradigm for GS is difficult given the nature of GS as diffusely infiltrating.

\begin{tabular}{|c|c|c|c|c|c|}
\hline Lead Author & Country & Primary Endpoint & $\begin{array}{l}\text { Number } \\
\text { of } \\
\text { Patients }\end{array}$ & $\begin{array}{l}\text { Overall } \\
\text { Survival } \\
\text { (Median) }\end{array}$ & Interventions \\
\hline $\begin{array}{l}\text { Castelli et al. } \\
2016[1]\end{array}$ & France & $\begin{array}{l}\text { To identify prognostic or therapeutic } \\
\text { variables impacting on OS in GS patients }\end{array}$ & 75 & 13 Months & Chemoradiotherapy \\
\hline $\begin{array}{l}\text { Adeberg et al. } \\
2016 \text { [5] }\end{array}$ & Germany & $\begin{array}{l}\text { To analyze effect of additional TMZ therapy } \\
\text { on GS patients }\end{array}$ & 37 & 13.4 Months & Chemoradiotherapy \\
\hline $\begin{array}{l}\text { Rath et al. } \\
2015 \text { [6] }\end{array}$ & India & $\begin{array}{l}\text { To analyze the outcome of treating } \\
\text { gliosarcoma with RT and TMZ by } \\
\text { measuring OS }\end{array}$ & 27 & 16.7 Months & Chemoradiotherapy \\
\hline $\begin{array}{l}\text { Singh et al. } \\
2015 \text { [7] }\end{array}$ & India & $\begin{array}{l}\text { To analyze the clinical, radiological, } \\
\text { histopathological, features of GS treated }\end{array}$ & 16 & 6 Months & Chemoradiotherapy \\
\hline $\begin{array}{l}\text { Cachia et al. } \\
2015 \text { [8] }\end{array}$ & $\begin{array}{l}\text { United } \\
\text { States }\end{array}$ & $\begin{array}{l}\text { To compare the overall survival and } \\
\text { pathological features of primary and } \\
\text { secondary gliosarcoma }\end{array}$ & 34 & 17.5 Months & Chemoradiotherapy \\
\hline $\begin{array}{l}\text { Kumar et al. } \\
2015 \text { [9] }\end{array}$ & India & $\begin{array}{l}\text { To evaluate the clinicopathological } \\
\text { variables and treatment outcomes in } \\
\text { patients of primary GS }\end{array}$ & 27 & 9 Months & Chemoradiotherapy \\
\hline $\begin{array}{l}\text { Damodaren et } \\
\text { al. } 2014 \text { [10] }\end{array}$ & Australia & $\begin{array}{l}\text { To review care for GSM patients and } \\
\text { compare survival with that of GBM patients }\end{array}$ & 19 & 9.7 Months & Chemoradiotherapy \\
\hline
\end{tabular}

\section{TABLE 5: Case Series Review Examining Studies with Gliosarcoma}

OS = Overall Survival; GS = Gliosarcoma; TMZ = Temozolomide; RT = Radiotherapy; GSM = Gliosarcoma; GBM = Glioblastoma .

Outcomes following GS resection have not been studied as extensively as those in glioblastoma patients due to GS's lower incidence. Kozak et al.'s [2] SEER study identified 353 GS patients over the age of 20 years in a 17-year period, amounting to an approximate annual incidence of one new case per 10,000,000 people over the age of 20 within the United States. In our study, GS accounted for approximately $2 \%$ of all high-grade gliomas treated at the Hospital of the University of Pennsylvania from January 2005 through January 2015. In accordance with previous studies, GS predominantly affected males in our study with a M/F ratio of 1.75:1. The median age of presentation was 63 years old, also similar to previous patient series. Studies 
have suggested there are statistically significant similar biological features of glioblastoma and GS [11], and our institution has treated both types of patients similarly in the above time period with surgical intervention being the primary step.

Overall, our study showed an increase in survival associated with the gross total resection group in comparison to the PR group. EOR was limited for the two patients in the PR group due to tumor location as one case involved an eloquent region and the other infiltrated across the corpus callosum. No significant difference was found between the STR and GTR group, suggesting no stepwise improvement in survival above a threshold level, which in our study was found to be an EOR of $94 \%$. This may in part be due to the more malignant nature of GS requiring a higher threshold for resection, although this study was not designed to support this theory.

Similar to other findings, our study found adjuvant chemoradiotherapy to be statistically associated with increased survival in univariate analysis. However, in our study, chemoradiotherapy was associated with increased survival during univariate analysis, but when adjusting for multivariate confounders did not maintain significance. This may also be due to the fact that the aggressiveness of GS in relation to glioblastoma makes it more resistant to adjunct treatment following surgical resection.

Studies have reported GS as having a greater propensity to metastasis [12-13] outside of the brain and this is believed to be due to the sarcomatous character of the tumor to spread hematogenously. Our series contained two (18\%) patients with multifocal lesions, and while multifocal lesions were statistically associated with differing survival in our study at the univariate level, it did not maintain significance in the multivariable analysis. It is plausible that the multifocal lesions are demonstrative of concomitant gliomas, which has been studied in one glioblastoma study [14], but to our knowledge, no such study has been completed for GS. However, given the aggressive nature of GS and its sarcomatous component, it is likely that these multifocal enhancing portions were part of the same infiltrating neoplasm since immunohistochemistry staining suggested a similar origin. In addition, our study included two (18\%) patients with leptomeningeal enhancement and one (9\%) patient with extracerebral metastasis.

As in other studies, both preoperative and postoperative KPS scores were associated with increased survival. In our study, two patients had improved performance postoperatively, while five patients remained at the same functional level postoperatively. However, there was no significant improvement in KPS scores recorded in association with the gross total resection category with this analysis, limited by the overall small sample size.

A lack of EGFR amplification in GS is a molecular marker that makes it distinct from glioblastoma. The frequency of EGFR amplification is known to be low in GS and is reported to be present in approximately $8 \%$ of cases [15-16]. Our study used immunohistochemistry staining to measure EGFR expression (scale 0-3), and three samples demonstrated strong $(+3)$ immunohistochemical expression; however, genetic profiling would be required to determine amplification status. In our study, no association was found between the results of EGFR staining and survival. Additionally, the Ki-67 index, a molecular marker for cell proliferation, demonstrated an association with decreased survival in this study.

The authors certainly note the limitations of this study as a retrospective cohort study of a specific population subset at one academic institution. It is important to note that the patients in the study differed in multiple clinical factors; however, our study agrees with overwhelming evidence in the study of high-grade gliomas that extent of resection is associated with increased survival. We also note our limited sample size and the biases from differences in 
patient characteristics that can influence results. Despite these limitations, our patient profiles were well indexed and thus we were able to analyze many clinical and immunohistochemistry factors associated with the tumor's outcomes. Additional studies will be necessary to determine the optimal balance between surgical and post-operative treatment for maximal survival in GS patients.

\section{Conclusions}

This study supports preexisting evidence from glioblastoma that there is an association between extent of resection and survival, and it suggests that this association is valid in GS patients. Our findings demonstrate that an EOR $>94 \%$ resection is associated with increased survival. Therefore, achieving an extent of resection above this threshold should be a priority for neurosurgeons treating patients with GS. In addition to maximum resection of the enhancing portion of the lesion, age (inversely), preoperative KPS, and postoperative KPS index are associated with lengthened survival and should be considered in determining a treatment plan for GS patients when possible.

\section{Additional Information}

\section{Disclosures}

Human subjects: Consent was obtained by all participants in this study. Animal subjects: All authors have confirmed that this study did not involve animal subjects or tissue. Conflicts of interest: In compliance with the ICMJE uniform disclosure form, all authors declare the following: Payment/services info: All authors have declared that no financial support was received from any organization for the submitted work. Financial relationships: All authors have declared that they have no financial relationships at present or within the previous three years with any organizations that might have an interest in the submitted work. Other relationships: All authors have declared that there are no other relationships or activities that could appear to have influenced the submitted work.

\section{References}

1. Castelli J, Feuvret L, Haoming Q, et al.: Prognostic and therapeutic factors of gliosarcoma from a multi-institutional series. J Neurooncol. 2016, 129:85-92. 10.1007/s11060-016-2142-9

2. Kozak KR, Mahadevan A, Moody JS: Adult gliosarcoma: epidemiology, natural history, and factors associated with outcome. Neuro Oncol. 2009, 11:183-191. 10.1215/15228517-2008-076

3. Louis D, Perry A, Reifenberger G, et al.: The 2016 World Health Organization classification of tumors of the central nervous system: a summary. Acta Neuropathol. 2016, 131:803-820. 10.1007/s00401-016-1545-1

4. Oppenlander ME, Wolf AB, Snyder LA, et al.: An extent of resection threshold for recurrent glioblastoma and its risk for neurological morbidity. J Neurosurg. 2014, 120:846-853. 10.3171/2013.12.JNS13184

5. Adeberg S, Bernhardt D, Harrabi SB, et al.: Radiotherapy plus concomitant temozolomide in primary gliosarcoma. J Neurooncol. 2016, 128:341-348. 10.1007/s11060-016-2117-x

6. Rath GK, Sharma DN, Mallick S, et al.: Clinical outcome of patients with primary gliosarcoma treated with concomitant and adjuvant temozolomide: a single institutional analysis of 27 cases. Indian J Cancer. 2015, 52:599-603. 10.4103/0019-509X.178407

7. Singh G, Das KK, Sharma P, et al.: Cerebral gliosarcoma: analysis of 16 patients and review of literature. Asian J Neurosurg. 2015, 10:195-202. 10.4103/1793-5482.161173

8. Cachia D, Kamiya-Matsuoka C, Mandel JJ, et al.: Primary and secondary gliosarcomas: clinical, molecular and survival characteristics. J Neurooncol. 2015, 125:401-410. 10.1007/s11060-0151930-y

9. Kumar N, Bhattacharyya T, Chanchalani K, Shalunke P, Radotra BD, Yadav BS: Impact of changing trends of treatment on outcome of cerebral gliosarcoma: a tertiary care centre experience. South Asian J Cancer. 2015, 4:15-17. 10.4103/2278-330X.149931 
10. Damodaran O, van Heerden J, Nowak AK, Bynevelt M, Mcdonald K, Marsh J, Lee G: Clinical management and survival outcomes of gliosarcomas in the era of multimodality therapy. J Clin Neruosci. 2014, 21:478-481. 10.1016/j.jocn.2013.07.042

11. Galanis E, Buckner JC, Dinapoli RP, et al.: Clinical outcome of gliosarcoma compared with glioblastoma multiforme: North Central Cancer Treatment Group results. J Neurosurg. 1998, 89:425-430. 10.3171/jns.1998.89.3.0425

12. Beaumont TL, Kupsky WJ, Barger GR, Sloan AE: Gliosarcoma with multiple extracranial metastases: case report and review of the literature. J Neurooncol. 2007, 83:39-46. 10.1007/s11060-006-9295-X

13. Han SJ, Yang I, Tihan T, Prados MD, Parsa AT: Primary gliosarcoma: key clinical and pathologic distinctions from glioblastoma with implications as a unique oncologic entity. J Neurooncol. 2010, 96:313-320. 10.1007/s11060-009-9973-6

14. Parsa AT, Wachhorst S, Lamborn KR, Prados MD, McDermott MW, Berger MS, Chang SM: Prognostic significance of intracranial dissemination of glioblastoma multiforme in adults . J Neurosurg. 2005, 102:622-628. 10.3171/jns.2005.102.4.0622

15. Actor B, Cobbers JM, Büschges R, Wolter M, Knobbe CM, Reifenberger G, Weber RG: Comprehensive analysis of genomic alterations in gliosarcoma and its two tissue components . Genes Chromosomes Cancer. 2002, 34:416-427. 10.1002/gcc.10087

16. Smith DR, Wu C, Saadatmand HJ, et al.: Clinical and molecular characteristics of gliosarcoma and modern prognostic significance relative to conventional glioblastoma. J Neurooncol. 2018, 137:303-311. 10.1007/s11060-017-2718-z 